\title{
Religious Involvement, Social Engagement, and Subjective Health Status of Older Residents of Informal Neighborhoods of Nairobi
}

Ivy Abla Kodzi, Stephen Obeng Gyimah, Jacques Emina, and Alex Chika Ezeh

\begin{abstract}
Although past research has extensively documented the effects of religious involvement and social integration on the health outcomes of older people, relatively little research has examined the relationship among older Africans. In this article, we examined the effects of religious affiliation and participation as well as forms of social engagement, including social support, sociability, and community participation on self-reported health. The study used data from a sample of older men and women (50 years and above) from two informal settlements in Nairobi Kenya. Differences in religious groups were statistically significant. Frequency of religious attendance was negatively associated with health, while the number of close friends, social support, and frequency of community participation were positively and independently related to self-reported health.
\end{abstract}

KEYWORDS Sub-Saharan Africa, Older people, Aging, Religion, Nairobi, Social interaction, Social engagement, Kenya

\section{INTRODUCTION}

The social support structures, including family networks and lineage systems, which sustained older people and ensured that their material and health needs were met are breaking down in most urban areas in sub-Saharan Africa today. The demands of urban life, growing poverty, and increased mortality of younger adults due to the HIV/ AIDS epidemic have resulted in increasing disengagement of adult children and younger kin who hitherto took care of the elderly. Increasingly, religious and community social organizations are replacing family support systems for older people. However, it is not empirically established whether religious involvement has positive effects on the health of older people in sub-Saharan Africa and particularly for urban residents.

The extensive scientific literature on the association between religious measures and various health outcomes suggests that religion has a protective effect on health. ${ }^{1,2}$ This evidence pertains even more strongly for older people. Various forms of religious involvement have been documented to be associated with improved physical and mental health, with better coping with morbidity or disability, and recovery from stressful life events such as death of loved ones, and ill-health associated with aging. ${ }^{3}$ Religious commitment also tends to be positively associated

Kodzi, Obeng Gyimah, Emina, and Chika Ezeh are with the African Population \& Health Research Center, Shelter Afrique Center, Nairobi, Kenya; Obeng Gyimah is with the Department of Sociology, Queens University, Kingston, ON, Canada.

Correspondence: Ivy Abla Kodzi, PhD, African Population \& Health Research Center, Shelter Afrique Center, P.O. Box 10787-00100 GPO, Longonot Road, Upper Hill, Nairobi, Kenya. (E-mail: ikodzi@aphrc.org) 
with various indices of subjective well-being. ${ }^{4,5}$ Notwithstanding the relevance of religion to the African social fabric, it is surprising that the relationship between religion and health has not been rigorously tested in the African context. The situation largely stems from the scarcity of requisite data to engage the topic. With the availability of data from informal settlements in Nairobi, the present study assesses the relationship among older people.

There are multiple theoretical pathways through which religion affects health. To different degrees, three dimensions of religious involvement may be related to health and well-being, namely, personal faith and spiritual experience, identification or affiliation with a religious community or group, and the level of participation in organized religious activities. ${ }^{6}$ First, personal faith and experience may influence an individual's worldview and interpretation of life and specific life experiences. Spiritually minded and highly religious people may draw on subjective elements of their spirituality in handling extenuating life situations. Religious practices such as prayer and meditation invariably affect the body's mechanism of handling stress and thus have positive effects on psychological and physical health. ${ }^{7-9}$ Second, religious denominations are distinctive in terms of the kinds of lifestyles proscribed. The extent of affiliation or identity with a particular religious group may inadvertently define a subculture or way of living that impacts one's health. For example, Pentecostals discourage drinking, smoking, and other lifestyle activities considered sinful or harmful to one's health. However, to the extent that denominations may tolerate pluralism of beliefs and may not enforce their distinctive practices and expectations, such blanket generalizations about the impact of religious affiliation may not hold. By and large, most religious institutions prohibit behaviors that are damaging to health and endorse health-promoting behaviors. ${ }^{10-12}$ Third, religion may facilitate the social integration of individuals through their participation in activities. The religious community is conducive for meeting likeminded people and for fostering relationships with people with common experiences. It has been extensively argued that the social interaction and support associated with religious participation, rather than the adherence of the religious doctrines, is the pathway through which religion affects health and well-being. Social support derived from religious communities may enhance individuals' ability to cope with stressful life events. Furthermore, the social aspects of religious community life, unlike other secular forms of social life, may facilitate adherence to preventive behavior, especially among older people. ${ }^{13,14}$

For older people, the social engagement argument is debatable. On the one hand, it is conceivable that it is good health that enables older individuals to participate in various forms of community life. ${ }^{15,16}$ On the other hand, the presence of illness and stressors could turn them to God. Besides, declining health tends to be associated with increased social support (especially instrumental help), making it tend to be typically negatively related to physical health but positively related to emotional health. ${ }^{17,18}$ Thus, in analyzing the influence of religion on health, one needs to control for the dimension of social integration, given that both may be potential determinants of health and well-being.

In this article, we investigate whether religious affiliation and participation (frequency of religious attendance) have unique effects on self-rated health after we control for indicators of social integration (including social support, sociability, and community organizational participation) and other determinants of self-rated health. Our objective is to ascertain whether religious and secular forms of social integration perform similar roles for older people living in Nairobi slums. We 
expect a positive relationship between religious belonging or affiliation (especially for denominations that strongly proscribe risky health behaviors), religiosity, and self-rated health. Furthermore, given the evidence that various aspects of individual social engagement have positive effects on health, we also expect that our measures of social engagement will maintain a positive effect on self-rated health over and above what is explained by religious engagement and other determinants. This study contributes to existing knowledge in that it is the first study that examines these relationships using data from older slum residents in sub-Saharan Africa. Examining the effects of religion and social engagement on health in the slum context is important because the setting is one of extreme deprivation where, in general, health outcomes are poor and religious involvement is high. Within this relatively homogenous setting, if one finds independent effects of religion and social engagement on subjective health, it underscores the strength of the effects.

\section{DATA AND METHODS}

We used the baseline data of an ongoing longitudinal study of older (50 years and above) men and women (2606) in two informal settlements in Nairobi. The data collection effort, which began in 2006, and is part of a 5-year research program titled "Urbanization, Poverty and Health Dynamics," is being implemented by the African Population and Health Research Center. Besides questions covering demographic and socioeconomic background and living arrangements, the older respondents were asked various questions requiring self-assessments of their health and well-being.

\section{Variables}

Health status, the outcome variable of interest, was measured as self-reported or self-rated general health. Self-rated health is a subjective assessment of one's own health and is usually captured on a Likert scale. This simple measure has been found to be predictive of functional health declines and mortality. ${ }^{1,19-21}$ The specific question asked was as follows: In general, how would you rate your health today? Would you say your health is "very good," "good," "moderate" "bad," or "very bad?" We reverse-coded this variable so that higher values mean better health status. For this analysis, we are interested in the effects of two substantive predictor variables. The first is religious commitment, captured in terms of affiliation and categorized as "Catholic"; "non-Catholic Christian"-comprising of protestant Christians, Pentecostals, and smaller Christian denominations; "Muslim"; and "no religion". Religious participation was coded as a dummy variable capturing whether the respondent attended religious services more than once a week or not. Catholics were used as the reference group because in Kenya, they tend to be relatively more accommodating of behaviors such as alcohol consumption, whereas Muslims and other Christian groups, particularly the Pentecostals, tend to emphasize such prohibitions through stricter social control. The second is social engagement-social interaction, support, and community participation. These variables include the number of close friends, whether the respondent receives material or financial support from relatives other than children, and an intensity of social participation composite index derived from three questions-frequency of attending social meetings in the last 4 months, frequency of community volunteering in the last 4 months, and frequency of meeting the community leader in the last 4 months. Chronbach's alpha for the social participation index is 0.93 , with an average 
interitem correlation of 0.87 , indicating that the index captures the construct of the intensity of social participation very well. Unfortunately, the data lack measures of specific religious practices and devotional intensity; consequently, we are unable to explore the effects of religious devotion on self-rated health. Finally, we included variables frequently found to be associated with self-rated health in the literature. These are demographic background factors, the existence of specific health problems, general physical functioning, and daily activity limitations. ${ }^{22}$ Table 1 presents the variables included in the model, together with the coding scheme used.

Since the dependent variable is ordinal in measurement, ordered logistic regression was used. The analysis begins with descriptive statistics followed by bivariate analysis of the predictor variables and self-rated health. In the multivariate analysis, we run a series of regression models, with self-rated health as the dependent variable in each of the models. The first model shows the effect of demographic and socioeconomic background variables on self-rated health. In subsequent models, we added blocks of variables capturing dimensions of religious involvement, social engagement, and functional health status.

\section{RESULTS}

The sample consisted predominantly of men (66\%) and married individuals $(70 \%)$, with about $70 \%$ between 50 and 60 years of age. The majority of respondents $(79 \%)$ had jobs or was engaged in some income-generating business. By way of educational attainment, the sample consisted mostly of people who had no schooling or had up to primary level schooling (79\%). About $5 \%$ did not state their educational level. Thirty percent of the sample was Catholic, $54 \%$ belonged to other Christian denominations, $12 \%$ were Muslims, and $4 \%$ reported that they belonged to no religious group. Table 2 (the bivariate analysis) shows that within slums, married individuals, "richer," economically engaged, and respondents with secondary education report better health, while women and older people report poorer health. Further, all the predictors of functional health were strongly related to self-rated health. Non-Catholic Christians were much more likely to report good health than Catholics, while Muslims reported worse health at the bivariate level. Frequency of religious attendance was negatively related to self-reported health. We also note that apart from the number of close friends, other predictors of social engagement did not have a significant association with self-rated health.

Table 3 presents the nested multivariate regression models. Model 1 shows that most of the demographic and socioeconomic background variables have significant effects on self-rated health. The effects of these control variables maintain the expected directions of association with self-rated health. Consistent with the literature, women, older individuals, and those in the poorest wealth quartile selfreport poorly on health status, while those currently married and currently working have positively rated their health status. The remaining models in Table 3 examine the effects of religion, social engagement, and functional health condition to ascertain whether religion and social engagement variables significantly affect selfrated health beyond the effects of the demographic, socioeconomic, and health variables. Model 2 incorporates the religious variables. Regarding religious affiliation, we find that the results observed at the bivariate level were maintained, with non-Catholic Christians being more likely to report good health than Catholics and Muslims being less likely to report good health than Catholics. In this model, frequency of religious attendance had a negative effect, although not statistically 


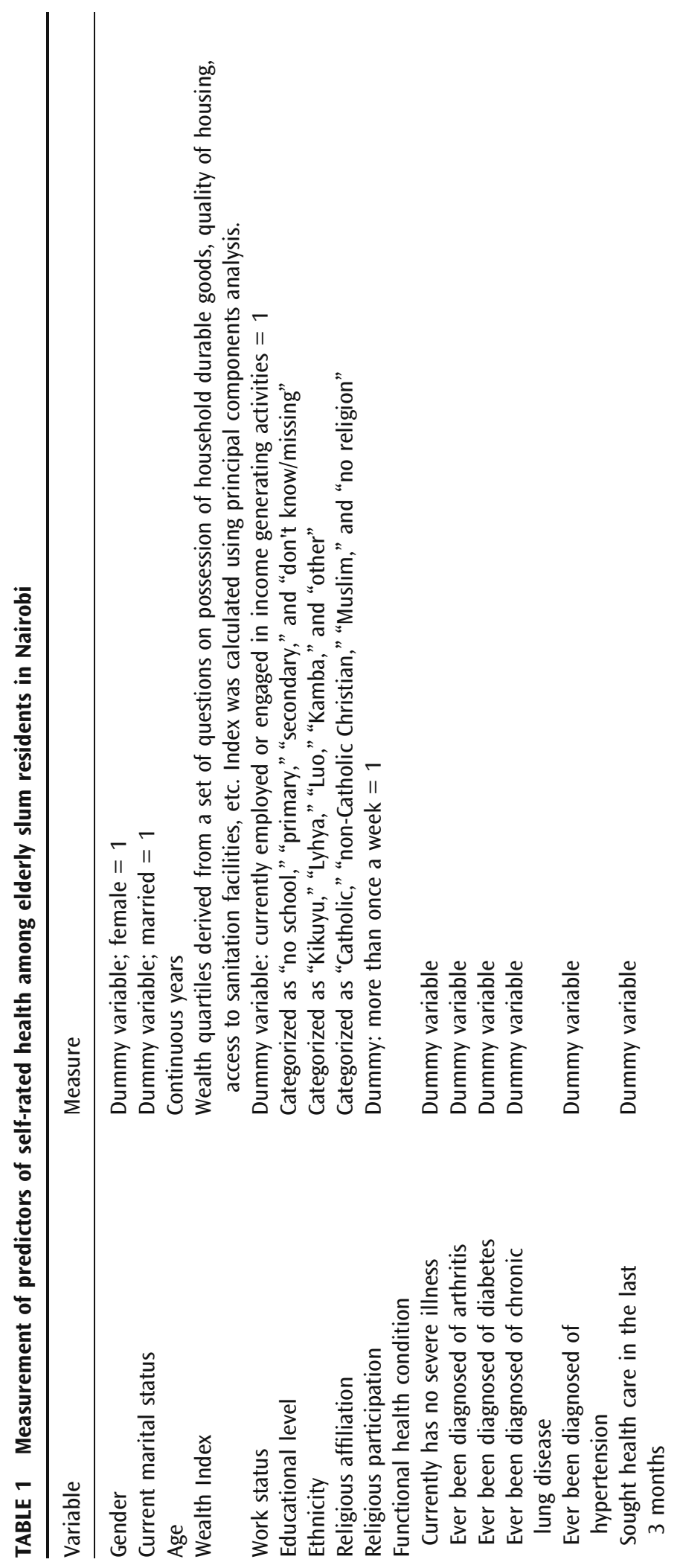




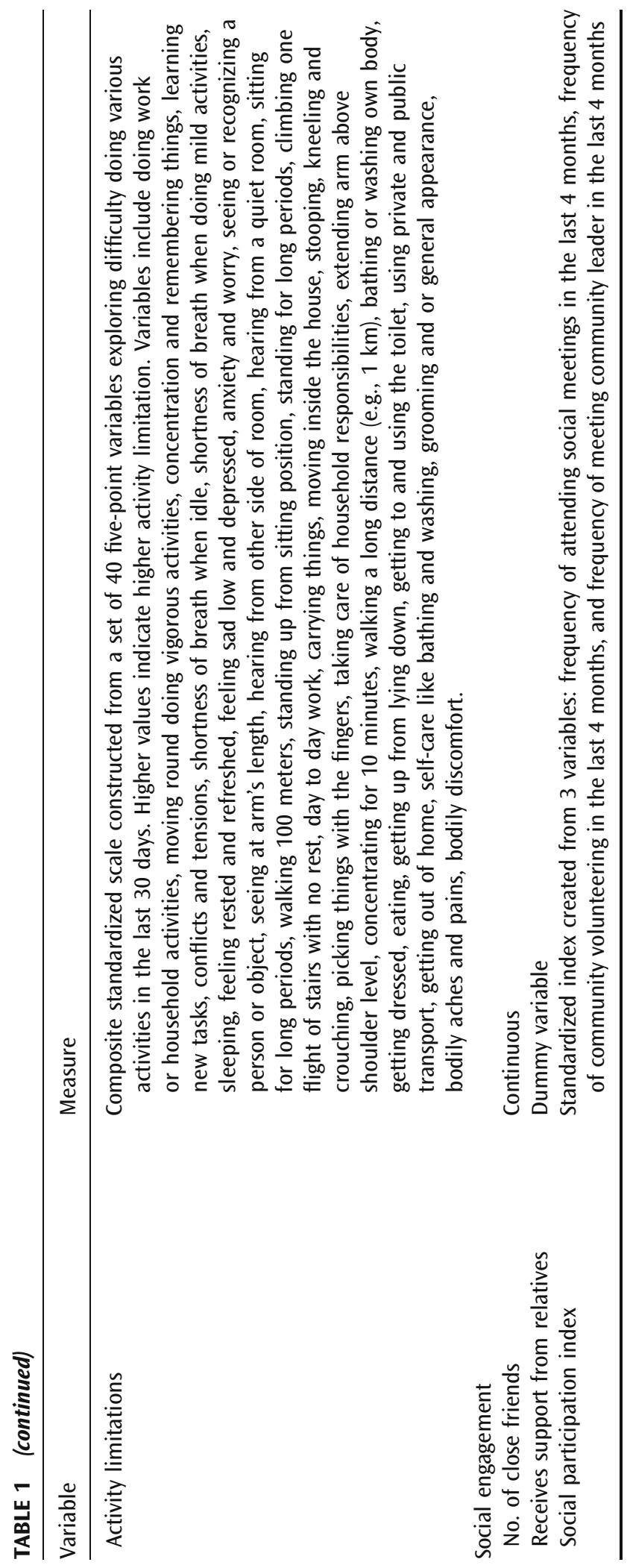


TABLE 2 Bivariate ordinal logistic regression results: effects (odds ratios) of predictors of selfrated health among elderly slum residents in Nairobi

\begin{tabular}{llll}
\hline & \%Distribution & Odds ratio & $P>|z|$ \\
\hline Background variables & & & \\
Female & 33.85 & 0.39 & 0.000 \\
Age (y) & $58.98^{\mathrm{a}}$ & 0.95 & 0.000 \\
Married & 70.42 & 2.51 & 0.000 \\
Poorest & 25.03 & 0.66 & 0.000 \\
Poor & 24.99 & 0.84 & 0.086 \\
Less poor & 24.99 & 0.86 & 0.057 \\
Least poor* & 24.99 & 1.00 & \\
Currently working & 79.06 & 4.12 & 0.000 \\
No school & 24.43 & 0.51 & 0.000 \\
Secondary & 16.37 & 1.40 & 0.001 \\
Schooling not stated & 4.84 & 0.38 & 0.000 \\
Primary* & 54.36 & 1.00 & \\
Luhya ethnicity & 12.56 & 1.29 & 0.028 \\
Luo ethnicity & 11.64 & 1.11 & 0.369 \\
Kamba ethnicity & 17.44 & 1.26 & 0.025 \\
Other ethnicity & 15.60 & 0.83 & 0.095 \\
Kikuyu ethnicity* & 42.76 & 1.00 & \\
Religious affiliation & & & \\
No Religion & 4.53 & 1.19 & 0.357 \\
Non-Catholic Christian & 53.86 & 1.30 & 0.002 \\
Muslim & 11.95 & 0.66 & 0.001 \\
Catholic & 29.66 & 1.00 & \\
Religious participation & & & \\
Attendance more than once a week & 17.02 & 0.72 & 0.001 \\
Social engagement & & & \\
No. of close friends & $4.75^{\mathrm{b}}$ & 1.03 & 0.000 \\
Social participation index & $0.00^{\mathrm{c}}$ & 1.03 & 0.572 \\
Receives material support from relatives & 10.56 & 1.06 & 0.619 \\
Functional health & & & \\
Currently has no severe illness & 45.26 & 9.45 & 0.000 \\
Activity limitation scale & $0^{\mathrm{c}}$ & 0.12 & 0.000 \\
Ever been diagnosed of arthritis & 16.67 & 0.32 & 0.000 \\
Ever been diagnosed of diabetes & 3.30 & 0.26 & 0.000 \\
Ever been diagnosed of chronic lung disease & 6.03 & 0.24 & \\
Ever been diagnosed of hypertension & 8.61 & 0.36 & \\
Sought health care in the last 3 months & 32.16 & & \\
\hline
\end{tabular}

\footnotetext{
${ }^{\mathrm{a}}$ Mean, with standard deviation (SD) of 8.99

${ }^{\mathrm{b}}$ Mean with SD of 7.32

${ }^{\mathrm{c}}$ Mean with SD of 1

*These are reference categories
}

significant. Model 3 adds on variables capturing social engagement. The directions and magnitudes of effects of the religious variables are substantially unchanged in this model, suggesting that religious involvement and social engagement contribute independently in explaining self-rated health. It is interesting to note that while the number of close friends and social support were significant predictors, the social participation index was not. The effect of the social participation index was, however, in the right direction. We finally control for functional health status, the 
TABLE 3 Multivariate ordinal logistic regression results: effects (odds ratios) of religious affiliation, religious participation, and social engagement on self-rated health among elderly slum residents in Nairobi

\begin{tabular}{|c|c|c|c|c|}
\hline & Model 1 & Model 2 & Model 3 & Model 4 \\
\hline \multicolumn{5}{|l|}{ Background variables } \\
\hline Female & $0.66^{* * *}$ & $0.66^{* * *}$ & $0.65^{* * *}$ & 0.86 \\
\hline Age $(y)$ & $0.98^{* * *}$ & $0.97^{* * *}$ & $0.97^{* * *}$ & 0.99 \\
\hline Married & $1.39 * *$ & $1.40^{* *}$ & $1.43^{* *}$ & 1.03 \\
\hline Poorest & $0.76^{*}$ & $0.77^{*}$ & $0.78^{*}$ & $0.79 *$ \\
\hline Poor & 0.89 & 0.89 & 0.91 & 0.98 \\
\hline Less poor & 0.87 & 0.87 & 0.89 & 0.98 \\
\hline Least poor ${ }^{\mathrm{a}}$ & 1.00 & 1.00 & 1.00 & 1.00 \\
\hline Currently working & $2.65^{* * *}$ & $2.62^{* * *}$ & $2.63^{* * *}$ & $1.73^{* * *}$ \\
\hline No school & 0.92 & 0.96 & 1.00 & 1.15 \\
\hline Secondary & 1.14 & 1.07 & 1.09 & 1.16 \\
\hline Schooling not stated & $0.64^{*}$ & $0.64^{*}$ & $0.66^{*}$ & 0.96 \\
\hline Primary ${ }^{\mathrm{a}}$ & 1.00 & 1.00 & 1.00 & 1.00 \\
\hline Luhya tribe & $0.81 \dagger$ & $0.80 \dagger$ & $0.79 \dagger$ & $0.77^{*}$ \\
\hline Luo tribe & $0.69^{*}$ & $0.70^{*}$ & $0.72^{*}$ & 0.84 \\
\hline Kamba tribe & 0.89 & 0.92 & 0.90 & 0.87 \\
\hline Other tribes & $0.82 \dagger$ & 1.17 & 1.16 & 1.16 \\
\hline Kikuyu tribe ${ }^{a}$ & 1.00 & 1.00 & 1.00 & 1.00 \\
\hline \multicolumn{5}{|l|}{ Religious affiliation } \\
\hline No religion & & 1.08 & 1.10 & 0.75 \\
\hline Non-Catholic Christian & & $1.26^{*}$ & $1.26^{*}$ & $1.30^{* *}$ \\
\hline Muslim & & $0.70 \dagger$ & $0.70 \dagger$ & 1.21 \\
\hline Catholics $^{\mathrm{a}}$ & & 1.00 & 1.00 & 1.00 \\
\hline \multicolumn{5}{|l|}{ Religious participation } \\
\hline Attendance more than once a week & & 0.93 & 0.91 & $0.79 *$ \\
\hline \multicolumn{5}{|l|}{ Social engagement } \\
\hline No. of close friends & & & $1.03^{* * *}$ & $1.02^{* * *}$ \\
\hline Social participation index & & & 1.07 & $1.25^{* * *}$ \\
\hline Receives material support from relatives & & & $1.29 *$ & $1.36^{*}$ \\
\hline \multicolumn{5}{|l|}{ Functional health } \\
\hline Currently has no severe illness & & & & $3.56^{* * *}$ \\
\hline Activity limitation scale & & & & $0.20^{* * *}$ \\
\hline Ever been diagnosed of arthritis & & & & 1.04 \\
\hline Ever been diagnosed of diabetes & & & & 0.77 \\
\hline Ever been diagnosed of chronic lung disease & & & & 0.77 \\
\hline Ever been diagnosed of hypertension & & & & 0.96 \\
\hline Sought health care in the last 3 months & & & & $0.46^{* * *}$ \\
\hline -2loglikelihood & -3075.58 & -3067.52 & -3048.24 & -2535.91 \\
\hline Psuedo- $R^{2}$ & 0.061 & 0.0629 & 0.069 & 0.225 \\
\hline$N$ & 2425 & 2425 & 2425 & 2425 \\
\hline
\end{tabular}

Legend: $\uparrow p<0.10,{ }^{*} p<0.05,{ }^{* *} p<0.01,{ }^{* * *} p<0.001$

predictor variable known to drive much of the variability in self-rated health among the elderly, in Model 4. In this final model, the social participation index becomes significant and the effect size increases. One would expect that the effect will be weaker than that observed in model 3 given that we were adjusting for variables that measure the extent of disability and physical limitations. Further, the other social 
engagement variables maintain significant effects in the final model. Moreover, in the final model, non-Catholic Christians were still more likely to report better health than Catholics. The direction of the effect changed for Muslims, but the effect is no longer significant. We also note that frequency of religious service attendance maintained its negative effect and gained significance in the final model. Finally, after controlling for functional health status, demographic variables such as gender, age, and marriage lost significance. However, dummy variables representing the poorest quartile, currently working, and Luhya ethnicity remain relatively stable in all the models.

\section{DISCUSSION AND CONCLUSION}

Our goal in this study was to ascertain the relationships between religious involvement (specifically the affiliative and participatory dimensions), social engagement, and self-rated health among elderly people living in informal settlements in Nairobi Kenya. We found no support for the hypothesis that forms of secular social engagement mediate the effects of religious affiliation and participation for elderly people. In our analyses, the religious variables maintained significance even when social integration had been adjusted for. Furthermore, both sets of variables had relatively strong direct associations with self-rated health.

Non-Catholic Christians were more likely to report better health than Catholics. A probable reason for the observed differences may lie in differences in the extent to which they emphasize doctrinal expectations regarding risky health behaviors and the associated subcultures defined by those expectations. Catholics tend to be more moderate than the non-Catholic Christians in Kenya, with majority belonging to more conservative religious institutions characterized by more social control. For example, non-Catholic religious groups tend to impose moral prohibitions on alcohol, smoking, and illicit drug consumption. This explanation may not, however, apply to Muslims. The effect of being Muslim was only marginally significant and the direction of association changed in the final model, suggesting that the differences between Catholics and Muslims may be due to underlying differences in actual health. Muslims may have more health conditions or physical limitations, which, once controlled for, do not make them different from Catholics, but they may tend to report better health after controlling for functional health status.

Furthermore, the stability of the effect of religious attendance across models demonstrates the relative importance of those religious factors that are not specific to any one particular denomination. More importantly for this sample, we observe that frequency of religious attendance was negatively associated with health. While this sound counterintuitive compared with studies in the Western world, it is conceivable that religion may be a means to cope with the stresses of poor healthreligious participation may invoke a sense of hope and optimism in dealing with failing health. However, since we have not controlled for prior actual- or selfreported health status, we are unable to decipher whether those with poor health were the ones tending to attend religious services more frequently.

We found evidence supporting the notion that secular forms of social engagement are positively associated with health. Koenig et al. ${ }^{2}$ reviewed several studies examining the relationship between social support and mental health and found a predominantly positive association. Further, there is considerable evidence in the medical literature about the positive effects of community and individual social capital as well as social interaction on various measures of health and well-being. 
This study adds to that body of knowledge, particularly in its application to the elderly in poor urban neighborhoods. Social policies should promote community participation on the backdrop of this evidence that stronger networks and participation within communities positively affect individual health.

Finally, our findings are also consistent with the larger literature on the determinants of self-rated health-that among the elderly, much of the variability in self-rated health is driven by variables related to their functional health status. Examining the percentage of variance explained by each of the models, it is clear that functional health status accounts for the bulk of the explanatory power of the models. This finding confirms the point that among older people, positive self-rated health is related to the absence of health problems and physical and emotional well-being.

\section{REFERENCES}

1. Koenig HG, Michael M, David L. Handbook of religion and health. New York: Oxford University Press; 2001.

2. Koenig HG. Religion and medicine II: religion, mental health and related behaviors. Int J Geriatr Psychiatr Med. 2001; 3(1): 97-109.

3. Matthews DA, McCullough M, Larson D, Koenig HG, Swyers J. Religious commitment and health status: a review of the research implications for family medicine. Arch Fam Med. 1998; 7(2): 118-124.

4. Koenig HG. Religious attitudes and practices of hospitalized medically-ill older adults. Int J Geriatr Psychiatr. 1998; 13(4): 213-224.

5. Ellison CG, Levin JS. The religion-health connection: evidence, theory and future directions. Health Educ and Behav. 1998; 25(6): 700-720.

6. Ellison CG, Gay D, Glass T. Does religious commitment contribute to individual life satisfaction? Soc Forces. 1989; 68(1): 100-123.

7. Carlson LE, Speca M, Patel KD, Goodey E. Mindfulness-based stress reduction in relation to quality of life, mood, symptoms of stress and levels of cortisol, dehydroepiandrosterone sulfate (DHEAS) and melatonin in breast and prostate cancer outpatients. Psychoneuroendocrinology. 2004; 29(4): 448-474.

8. Seeman T, Dubin L, Seeman M. Religiousity/spirituality and health. A critical review of biological pathways. American Psychol. 2003; 58(1): 53-63.

9. Morris EL. The relationship between spirituality and coronary heart disease. Alternative Ther health Med. 2001; 7(5): 96-98.

10. Reindl Benjamins M, Brown C. Religion and preventive health care utilization among the elderly. Soc Sci Med. 2004; 58(1): 109-118.

11. Crowther MR, Parker M, Achenbaum W, Larimore W, Koenig HG. Rowe and Kahn's model of successful aging revisited: positive spirituality-the forgotten factor. Gerontologist. 2002; 42(5): 613-620.

12. Strawbridge WJ, Shema S, Cohen RD, Kaplan DA. Religious attendance increases survival by improving and maintaining good health behaviors, mental health and social relationships. Ann of Behav Med. 2001;23(1):68-74.

13. Flannelly EK, Ellison CG, Stroke AL. Methodology issues in research on religion and health. South Med J. 2004; 97(12): 1231-1241.

14. Thoresen CE, Harris AH. Spirituality and health. What's the evidence and what's needed? Ann Behav Med. 2002; 24(1): 3-13.

15. Powell LH, Shahabi L, Thoresen C. Religion and spirituality: linkages to physical health. Am Psychol. 2003; 58(1): 36-52.

16. McCullough ME, Hoyt W, David L, Koenig HG, Thoresen C. Religious involvement and mortality: a meta-analytic review. Br J Health Psychol. 2000; 19(3): 211-222.

17. Yeager DM, Glei D, Au M, Lin HS, Sloan R, Weistein M. Religious involvement and health outcomes among older persons in Taiwan. Soc Sci and Med. 2006; 63: 2228-2241. 
18. Deeg DJH, Kriegsman DM. Concepts of self-rated health: specifying the gender difference in mortality risk. Gerontologist. 2003; 43: 376-386.

19. Idler EL, Hudson S, Leventhal $\mathrm{H}$. The meanings of self-ratings of health: a qualitative and quantitative approach. Res Aging. 1999; 21: 458-476.

20. Idler EL, Russell IB, Davis D. Survival, functional limitations, and self-rated health in the NHANES I epidemiological follow-up study, 1992. Am J Epidemiol. 2000; 152: 874883.

21. Idler EL, Benyamini Y. Self-rated health and mortality: a review of twenty-seven community studies. J Health Soc behav. 1997; 38: 21-37.

22. Cheng ST, Chan A. Social Support and self-rated health revisited: is there a gender difference in later life. Soc Sci \& Med. 2006; 63: 118-122. 